\title{
Nitrato modula os teores de cloreto e compostos nitrogenados em plantas de milho submetidas à salinidade
}

\author{
Alexcyane Rodrigues Feijão ('); Elton Camelo Marques ('); Júlio César Barbosa da Silva (); \\ Claudivan Feitosa de Lacerda (3); José Tarquinio Prisco ( $\left.{ }^{4}\right)$; Enéas Gomes-Filho $\left({ }^{4 *}\right)$ \\ (') Universidade Federal do Ceará (UFC), Programa de Pós-Graduação em Bioquímica, Caixa Postal 6039, 60440-970 Fortaleza \\ (CE), Brasil. \\ (2) UFC, Curso de Ciências Biológicas, 60440-970 Fortaleza (CE), Brasil. \\ (3) UFC, Departamento de Engenharia Agrícola e Instituto Nacional de Ciência e Tecnologia em Salinidade (INCTSal/CNPq), \\ 60440-554 Fortaleza (CE), Brasil. \\ (4) UFC, Departamento de Bioquímica e Biologia Molecular e INCTSal/CNPq, 60440-970 Fortaleza (CE), Brasil. \\ (*) Autor correspondente: egomesf@ufc.br
}

Recebido: 14/nov./2012; Aceito: 3/abr./2013

\begin{abstract}
Resumo
O objetivo deste trabalho foi estudar o efeito do nitrato $\left(\mathrm{NO}_{3}^{-}\right)$no crescimento e no acúmulo de solutos inorgânicos e orgânicos em plantas de milho submetidas à salinidade. O delineamento experimental foi o inteiramente casualizado, com cinco repetições, sob esquema fatorial $2 \times 4$, constando de oito tratamentos: dois níveis de salinidade $(\mathrm{NaCl}$ a 0 e $75 \mathrm{mM})$ e quatro concentrações de $\mathrm{NO}_{3}^{-}(0,5 ; 2,5 ; 5,0$ e 7,5 mM) em sistema hidropônico. A massa seca da parte aérea e das raízes foi reduzida pela salinidade, porém isso foi menos evidente quando as plantas foram submetidas a concentrações de $\mathrm{NO}_{3}$ - abaixo de 2,5 mM. O melhor crescimento das plantas foi observado na concentração aproximada de $\mathrm{NO}_{3}{ }^{-}$a 5,0 mM. Os teores de $\mathrm{Na}^{+}$e $\mathrm{Cl}^{-}$aumentaram com a salinidade em todos os órgãos estudados, havendo maior acúmulo desses íons nas raízes. De modo geral, os teores de $\mathrm{K}^{+}$foram pouco afetados por esse estresse. Com o aumento da concentração de $\mathrm{NO}_{3}$ - no meio, houve melhora na absorção desse íon, levando à redução da absorção de $\mathrm{Cl}^{-}$e ao acúmulo de prolina e $\mathrm{N}$-aminossolúveis. $\mathrm{O}$ estresse nutricional é mais limitante ao crescimento das plantas de milho que o estresse salino, cujos efeitos prejudiciais são minimizados por uma nutrição de $\mathrm{NO}_{3}{ }^{-}$adequada.
\end{abstract}

Palavras-chave: estresse salino, nitrogênio, solutos inorgânicos e orgânicos, Zea mays.

\section{Nitrate modulates the contents of chloride and $\mathrm{N}$-compounds in maize plants under salinity}

\section{Abstract}

This work aimed to study the effect of nitrate $\left(\mathrm{NO}_{3}^{-}\right)$on growth and accumulation of inorganic and organic solutes in maize plants subjected to salinity. The experiment was carried out in a completely randomized design, with five replications, and a $2 \times 4$ factorial scheme, consisting of eight treatments: two salinity levels $(\mathrm{NaCl}$ at 0 or $75 \mathrm{mM}$ ) and four different concentrations of $\mathrm{NO}_{3}-(0.5,2.5,5.0$ or $7.5 \mathrm{mM})$ in nutrient solution. The dry mass of shoots and roots was reduced by salinity, however, this was less evident when plants were exposed to concentrations of $\mathrm{NO}_{3}$ - below $2.5 \mathrm{mM}$. The best growth was observed in the approximate concentration of $5.0 \mathrm{mM} \mathrm{NO}_{3}$. The $\mathrm{Na}^{+}$and $\mathrm{Cl}^{-}$contents increased with salinity in all organs studied, and the highest accumulation of these ions was observed in the roots. In general, the $\mathrm{K}^{+}$content was not severely affected by this stress. With the increase of $\mathrm{NO}_{3}{ }^{-}$concentration in the medium, there was an improvement in the absorption of this ion, leading to reduced uptake of $\mathrm{Cl}^{-}$and the accumulation of proline and soluble amino acids. Nutritional stress is more limiting to plant growth of maize than the salt stress, with harmful effects being alleviated by an adequate nutrition of $\mathrm{NO}_{3}$ :

Key words: salt stress, nitrogen, inorganic and organic solutes, Zea mays. 


\section{INTRODUÇÃO}

A salinidade é um dos estresses abióticos que mais limitam o crescimento e a produtividade agrícola. Aproximadamente $20 \%$ das terras cultivadas no mundo vêm enfrentando problemas de salinização, sendo mais severos nas regióes áridas e semiáridas (Munns e TeSTER, 2008).

A redução do crescimento causada pela salinidade é decorrente de seus efeitos osmóticos, tóxicos e nutricionais sobre as plantas (Munns e TeSTER, 2008). Os distúrbios nutricionais associados ao estresse salino podem resultar $\mathrm{da}$ redução da disponibilidade de nutrientes (pela competiçấo na absorção e no transporte dentro da planta), da alteração da integridade estrutural e funcional da membrana plasmática, bem como da inibição da atividade de várias enzimas vitais do metabolismo (Mansour e Salama, 2004; Alvarez-Pizarro et al., 2009; Aragão et al., 2010). Dessa forma, a salinidade pode levar à deficiência de nutrientes essenciais e ao excesso de íons tóxicos nas plantas.

Entre os principais elementos essenciais destaca-se o nitrogênio $(\mathrm{N})$, que é constituinte de muitas biomoléculas, tais como proteínas, ácidos nucleicos e aminoácidos (McAllister et al., 2012), sendo, portanto, requerido em altas concentraçôes pelas plantas. A deficiência de $\mathrm{N}$ inibe rapidamente o crescimento e, consequentemente, a produção vegetal (Williams e Miller, 2001; McAllister et al., 2012). O N está disponível às plantas principalmente como uma mistura de $\mathrm{NH}_{4}^{+}$e $\mathrm{NO}_{3}$, sendo esse último íon a forma predominante (MilLER et al., 2007).

A salinidade interfere na aquisição e na utilização do N. Assim, condiçôes de salinidade podem influenciar a absorção, distribuiçáo e assimilação do $\mathrm{N}$, assim como a síntese de proteínas (ABD-El BAKI et al., 2000; Ebert et al., 2002; Debouba et al., 2006; Tabatabaei, 2006; AragẤo et al., 2010). De maneira geral, solos salinizados são deficientes em $\mathrm{N}$ e, dessa forma, a baixa disponibilidade desse elemento tem sido sugerida como um dos principais fatores responsáveis pela redução do crescimento das plantas em condições de salinidade (FAgeria et al., 2011). Alguns estudos têm revelado que o aumento da fertilizaçáo nitrogenada pode reduzir os efeitos deletérios do estresse salino e promover o crescimento das plantas (EBERT et al., 2002; Barhoumi et al., 2010). Esse processo ocorre porque nessas condiçôes há maior acúmulo de compostos orgânicos contendo $\mathrm{N}$ (por exemplo, prolina, aminoácidos livres e glicinabetaína) (Munns e Tester, 2008), os quais associados ao nitrato em excesso no vacúolo baixam o potencial osmótico da planta, contribuindo diretamente para o ajustamento osmótico (Miller et al., 2007; Ding et al., 2010). Tais compostos também auxiliam na homeostase iônica celular, contribuem como fonte de carbono e nitrogênio em condiçóes de fotossíntese e crescimento limitados, estabilizam proteínas e membranas e removem radicais livres (Parida e Das, 2005; Azevedo Neto et al., 2009).
O milho (Zea mays L.) é uma espécie considerada moderadamente sensível ao excesso de sais no solo (MaAs e Hoffman, 1977) e o efeito da salinidade sobre o crescimento e o acúmulo de íons e solutos orgânicos nessa espécie já é bem documentado (ABD-El BAKI et al., 2000; Azevedo Neto et al., 2004; Azevedo Neto et al., 2009; CARpici et al., 2010). Contudo, estudos sobre a interação entre salinidade e $\mathrm{N}_{-} \mathrm{NO}_{3}^{-}$são escassos nessa espécie e bastante relevantes, visto que o $\mathrm{N}$ é o nutriente mineral mais exigido por essa cultura (MACHADO et al., 2004). Diante do exposto, o objetivo deste trabalho foi estudar os efeitos do nitrato no crescimento e no acúmulo de solutos inorgânicos e orgânicos em plantas de milho submetidas à salinidade e verificar se o aumento da nutrição de nitrato é capaz de reduzir os efeitos deletérios do estresse salino nesta cultura.

\section{MATERIAL E MÉTODOS}

Sementes de milho (Zea mays L.), do genótipo BR5011, foram selecionadas e, em seguida, esterilizadas superficialmente durante 5 minutos com hipoclorito de sódio, contendo cloro ativo a $0,7 \%$. Depois disso, as sementes foram exaustivamente lavadas com água destilada, para a retirada do hipoclorito, e semeadas em copos plásticos $(200 \mathrm{~mL})$ contendo vermiculita umedecida com água destilada, sendo mantidos em casa de vegetaçáo. Decorridos sete dias da semeadura, as plântulas foram transferidas para bandejas plásticas contendo $10 \mathrm{~L}$ de solução nutritiva de Clark (Clark, 1975) (diluída 1:2). Após cinco dias, a solução nutritiva foi trocada por uma nova (não diluída), na qual as plantas permaneceram por mais dois dias para aclimatação.

Aos 14 dias após a semeadura, as plantas foram transferidas para vasos (uma planta por vaso) contendo $3 \mathrm{~L}$ de soluçáo nutritiva de Clark modificada, tendo o $\mathrm{NO}_{3}^{-}$ como única fonte de nitrogênio, nas concentraçôes de 0,5 ; 2,5; 5,0 ou 7,5 mM, e cultivadas na ausência (controle) ou presença de $\mathrm{NaCl}$, que foi adicionado em parcelas de $25 \mathrm{mM}$, a cada 48 horas, até atingir a concentração final de $75 \mathrm{mM}$. A fonte de nitrato utilizada foi o $\mathrm{Ca}\left(\mathrm{NO}_{3}\right)_{2}$. Durante o experimento, o volume da soluçáo nutritiva perdido por evapotranspiraçáo foi reposto pela adição diária de água destilada. A solução foi trocada por uma nova a cada cinco dias, ocasiáo na qual o seu $\mathrm{pH}$ foi ajustado para 5,5 pela adição de $\mathrm{NaOH}$ a $0,1 \mathrm{M}$ ou $\mathrm{HCl}$ a $0,1 \mathrm{M}$. Os valores médios da temperatura diurna e noturna e da umidade relativa do ar, no interior da casa de vegetação, foram, respectivamente, de $31,1 \pm 1,5{ }^{\circ} \mathrm{C} ; 27,4 \pm 1,1{ }^{\circ} \mathrm{C}$ e $65,5 \pm 2,0 \%$.

As plantas foram coletadas após 15 dias do início da adiçâo de sal, sendo divididas em folhas, colmos e raízes. Nessa ocasião, foi determinada a área foliar (AF), em aparelho LI-COR ${ }^{\oplus}$ mod. LI-3100 (Lincoln, Nebraska, USA). O material coletado foi congelado a $-20{ }^{\circ} \mathrm{C}$ e, em 
seguida, liofilizado. Após esse processo, foi determinada a massa seca da parte aérea (MSPA) e das raízes (MSR). O material liofilizado foi macerado e o pó obtido, armazenado a $-20{ }^{\circ} \mathrm{C}$ para posterior utilizaçáo.

Os extratos para a determinação dos teores de íons inorgânicos foram preparados como descrito por Cataldo et al. (1975), com pequenas modificaçóes. Em tubos de ensaio, foram adicionados $10 \mathrm{~mL}$ de água desionizada a $100 \mathrm{mg}$ do pó liofilizado de folhas, colmos ou raízes. As amostras foram agitadas e incubadas a $45^{\circ} \mathrm{C}$, por 1 hora, em banho-maria, sendo os tubos agitados a cada 15 minutos. Em seguida, as amostras foram centrifugadas por 15 minutos a $3.000 \times g$, à temperatura ambiente, sendo o sobrenadante (extrato) coletado, filtrado em papel de filtro e armazenado a $4{ }^{\circ} \mathrm{C}$. Os teores de $\mathrm{Na}^{+}$e de $\mathrm{K}^{+}$foram determinados por fotometria de chama. Os teores de $\mathrm{Cl}^{-}$ foram determinados segundo o método de GaINEs et al. (1984), enquanto os teores de $\mathrm{NO}_{3}^{-}$, por meio do método do ácido salicílico (CATALdo et al., 1975).

O extrato para determinação dos solutos orgânicos foi obtido a partir da homogeneização, em almofariz, de $150 \mathrm{mg}$ do pó liofilizado de folhas, colmos ou raízes com $6 \mathrm{~mL}$ de tampáo fosfato de potássio a $100 \mathrm{mM}$, $\mathrm{pH} 7,0$, contendo EDTA a 0,1 mM. O homogeneizado foi filtrado em tecido de náilon de malha fina e centrifugado durante 15 minutos a $12.000 \times g$, a $4^{\circ} \mathrm{C}$. O sobrenadante (extrato) foi armazenado a $-20^{\circ} \mathrm{C}$ até o momento das análises. Os teores de carboidratos solúveis, prolina e $\mathrm{N}$-aminossolúveis foram determinados de acordo com Dubois et al. (1956), Bates et al. (1973) e Yemm e Cocking (1955) respectivamente.

$\mathrm{O}$ delineamento experimental utilizado foi o inteiramente casualizado, em esquema fatorial $2(\mathrm{NaCl}$ a 0 ou $75 \mathrm{mM}) \times 4\left(\mathrm{NO}_{3}^{-}\right.$a 0,$5 ; 2,5 ; 5,0$ ou $\left.7,5 \mathrm{mM}\right)$, com cinco repetiçôes. Os resultados foram submetidos à análise de variância e o efeito da concentraçáo de nitrato avaliado mediante análise de regressão, cujo modelo foi escolhido com base na significância dos coeficientes de regressão, associada ao maior valor do coeficiente de determinação $\left(\mathrm{R}^{2}\right)$.

\section{RESULTADOS E DISCUSSÃO}

O crescimento das plantas de milho em condiçóes-controle e de salinidade, sob níveis crescentes de nitrato $\left(\mathrm{NO}_{3}^{-}\right)$, está representado na figura 1 . Houve efeito interativo entre a concentração de $\mathrm{NO}_{3}^{-}$e a salinidade apenas na MSPA e na MSR, visto que nessas variáveis o efeito da salinidade dependeu da concentraçáo de $\mathrm{NO}_{3}{ }_{3}^{-}$presente no meio de crescimento (Figura 1a,b). Os valores da MSPA das plantas-controle e em estresse salino ajustaram-se ao modelo quadrático de regressão e foram máximos nas concentraçôes estimadas, respectivamente, de $\mathrm{NO}_{3}{ }_{3}^{-}$de 5,4 e 5,1 mM. Contudo, a salinidade reduziu significativamente esse parâmetro e sendo mais acentuado quando as concentraçôes de $\mathrm{NO}_{3}^{-}$no meio de cultivo foram mais elevadas (Figura 1a).

A MSR proporcionou valores máximos nas concentraçôes estimadas de $\mathrm{NO}_{3}^{-}$de 5,0 e 4,4 mM, respectivamente, em condiçóes-controle e de salinidade (Figura 1b). O crescimento radicular das plantas pareceu ser mais limitado pela salinidade do que o da parte aérea, em comparação com seus respectivos controles (Figura 1a,b). Esse fato foi corroborado pelo aumento significativo da relação entre a massa seca da parte aérea e das raízes (MSPA/MSR), em condiçôes de salinidade, mesmo sem ter havido interação significativa entre os fatores analisados (Figura 1c). Além disso, o aumento da concentração de $\mathrm{NO}_{3}^{-}$não influenciou significativamente a MSPA/MSR.

A salinidade reduziu significativamente a AF das plantas de milho e o aumento da concentraçấo de $\mathrm{NO}_{3}^{-}$resultou em valores máximos dessa variável na concentração estimada de 5,4 mM (Figura 1d). No entanto, não houve interação significativa entre a concentração de $\mathrm{NO}_{3}^{-}$e a salinidade na AF das plantas de milho.

A salinidade inibiu o crescimento das plantas de milho, como demonstrado anteriormente (ABD-EL BAKI et al., 2000; Azevedo Neto et al. 2004; Carpici et al., 2010), porém, a baixas concentraçốes de $\mathrm{NO}_{3}^{-}$, a carência de $\mathrm{N}$ preponderou, sendo provavelmente o fator mais limitante do crescimento; a MSPA e a MSR das plantas crescidas em concentraçôes de $\mathrm{NO}_{3}^{-}$abaixo de 2,5 mM foram bem menores que os valores daquelas crescidas acima dessa concentração de $\mathrm{NO}_{3}^{-}$, mesmo em condiçóes-controle. Com altos níveis de $\mathrm{NO}_{3}^{-}$, o fator preponderante na redução do crescimento foi o estresse salino (Figura 1). Resultados semelhantes foram observados no tomateiro (Deвouba et al., 2006) e na halófita Tamarix laxa (Ding et al., 2010). De maneira geral, o melhor crescimento das plantas de milho foi observado quando a concentração de $\mathrm{NO}_{3}^{-}$, no meio de cultivo, foi aproximadamente de 5,0 mM, tanto em condiçôes-controle como de estresse salino, mostrando que essa concentração é suficiente para suprir o crescimento máximo dessa espécie. Vários autores relatam a importância do $\mathrm{N}$ para o crescimento das plantas, sendo a deficiência desse elemento um fator importante para a rápida inibição desse processo (BARHOUmI et al., 2010; Ding et al., 2010). De modo geral, a adição de N melhora a produçáo e o crescimento das plantas, estando submetidas ou não ao estresse salino (Deвouba et al., 2006; BARHOUMI et al., 2010).

Os teores de $\mathrm{Na}^{+}$foram aumentados pela salinidade, havendo maior acúmulo nas raízes, seguidas dos colmos e das folhas; o aumento da concentração de $\mathrm{NO}_{3}^{-}$, por sua vez, influenciou essa variável apenas nas condiçóes-controle (Figura 2a,c,e). Diferentemente do que foi observado neste trabalho, o aumento do suprimento de $\mathrm{NO}_{3}$ pôde reduzir a concentração de $\mathrm{Na}^{+}$tanto na parte aérea quanto na raiz da halófita Tamarix laxa, em condiçōes de salinidade (Ding et al., 2010). O Na+ acumulou-se 

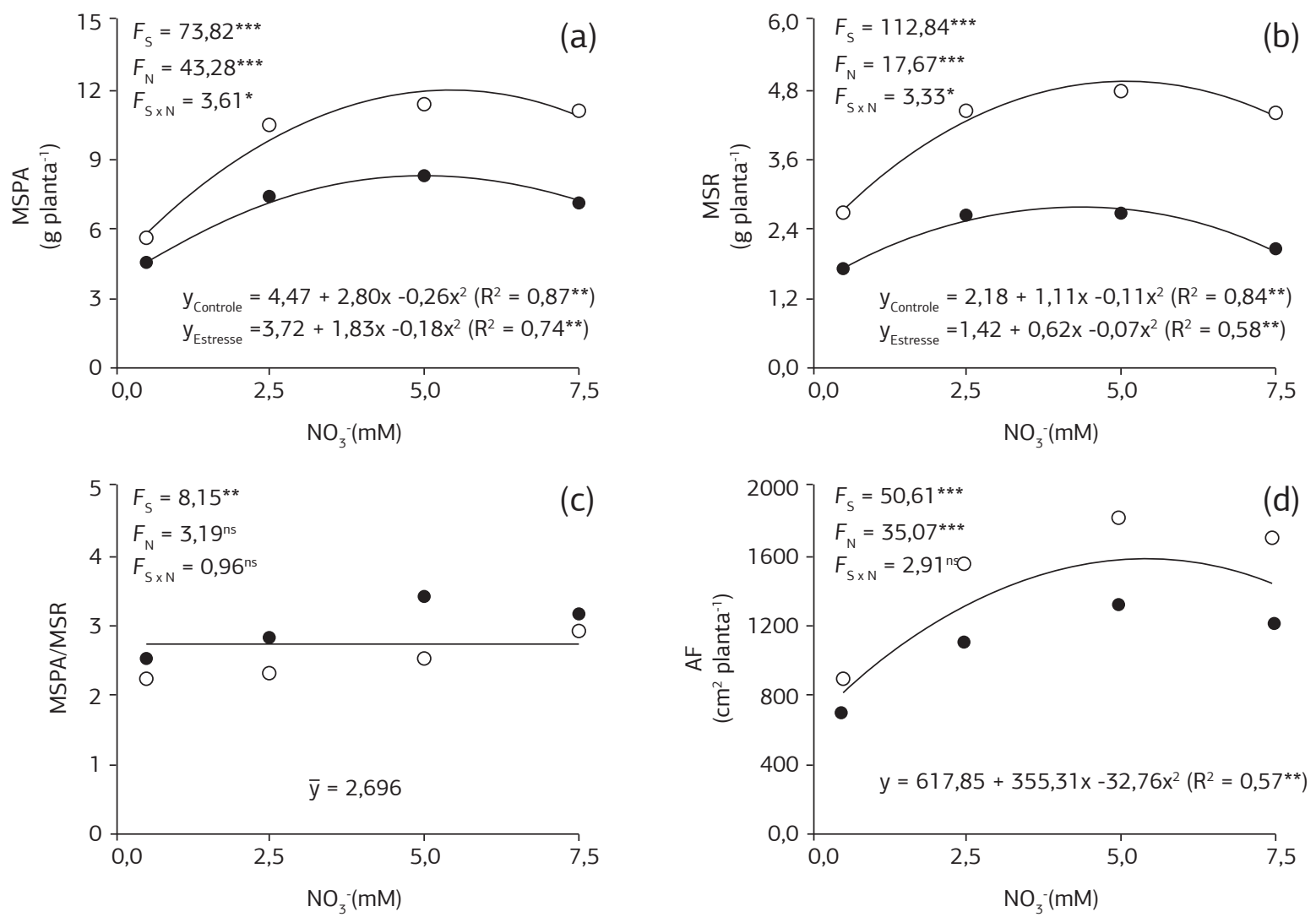

Figura 1. Massa seca da parte aérea (MSPA, a) e das raízes (MSR, b), relação MSPA/MSR (c), e área foliar (AF, d) de plantas de milho (Zea mays L.) em condiçóes controle $(\bigcirc)$ e de estresse salino $(-)$ em função da concentração de $\mathrm{NO}_{3}$. No canto superior esquerdo, estâo representados os valores de $F$ para salinidade $\left(F_{S}\right)$, nitrato $\left(F_{\mathrm{N}}\right)$ e interação entre salinidade e nitrato $\left(F_{S \times \mathrm{N}}\right)$. Níveis de significância: ${ }^{* * *} \mathrm{p} \leq 0,001 ;{ }^{* *} \mathrm{p} \leq 0,01 ;{ }^{*} \mathrm{p} \leq 0,05 ;{ }^{\text {ns: }}$ náo significativo.

preferencialmente nas raízes das plantas de milho submetidas à salinidade, fato que já foi observado anteriormente (Azevedo Neto et al., 2004), demonstrando a capacidade dessa espécie em controlar o transporte de $\mathrm{Na}^{+}$para os tecidos fotossintéticos. De acordo com Munns (2002), plantas tolerantes aos sais possuem baixas taxas de transporte de $\mathrm{Na}^{+}$e $\mathrm{Cl}^{-}$para a parte aérea, sendo ainda capazes de compartimentar esses íons no vacúolo, prevenindo o acúmulo deles no citoplasma e evitando a toxicidade pelos sais.

Os teores de $\mathrm{K}^{+}$, por sua vez, foram influenciados significativamente pelo $\mathrm{NO}_{3}^{-}$apenas nas raízes, nas quais eles foram reduzidos em ambos os níveis de salinidade (Figura 2b,d,f). Contudo, quando a concentração de $\mathrm{NO}_{3}{ }^{-}$foi menor que $2,5 \mathrm{mM}$, os teores desse ín nas raízes, em condiçôes de salinidade, permaneceram menores que aqueles observados nas condiçóes controle (Figura 2f). Alguns trabalhos revelaram que o aumento da disponibilidade de $\mathrm{N}$ não influenciou os teores de $\mathrm{K}^{+}$ (TABatabaei, 2006; Ding et al., 2010), enquanto outros observaram que a absorçáo de $\mathrm{K}^{+}$dependeu do suprimento de $\mathrm{N}$, o que foi verificado tanto em condiçóes-controle quanto de salinidade (Barhoumi et al., 2010). A manutenção dos teores de $\mathrm{K}^{+}$é sugerida como um mecanismo comum de proteção contra os efeitos tóxicos dos sais, uma vez que a manutenção de altas concentraçóes de $\mathrm{K}^{+}$no citosol é requerida para uma homeostase iônica celular adequada (Munns e Tester, 2008; Rodrigues et al., 2013). Adicionalmente, a relaçáo $\mathrm{K}^{+} / \mathrm{Na}^{+}$pode ser considerada um critério de seleçáo de materiais sensíveis e tolerantes aos sais (Flowers, 2004; Parida e Das, 2005). O comprometimento do estado nutricional das plantas, em termos de $\mathrm{K}^{+}$, pelo aumento da absorção de $\mathrm{Na}^{+}$, sob estresse salino, é um fenômeno bastante conhecido (Azevedo Neto et al., 2004; Alvarez-Pizarro et al., 2009), mas não foi evidente neste estudo.

A salinidade aumentou os teores de $\mathrm{Cl}^{-}$nas diversas partes das plantas de milho, mas apenas nos colmos e nas raízes é que esse efeito foi dependente da concentração de $\mathrm{NO}_{3}{ }^{-}$presente no meio (Figura 3a,c,e). Nos colmos, em condiçôes de salinidade, os teores de $\mathrm{Cl}^{-}$diminuíram até a concentração estimada de 4,9 $\mathrm{mM}$ de $\mathrm{NO}_{3}^{-}$(Figura 3c). Nas raízes, os teores de $\mathrm{Cl}^{-}$foram reduzidos com o aumento da concentraçáo de $\mathrm{NO}_{3}^{-}$, em ambos os níveis de $\mathrm{NaCl}$ (Figura 3e). Com esses resultados, verifica-se que maiores suprimentos de $\mathrm{NO}_{3}{ }^{-}$reduzem a absorção de $\mathrm{Cl}^{-}$, que é um íon tóxico, aumentando consequentemente 

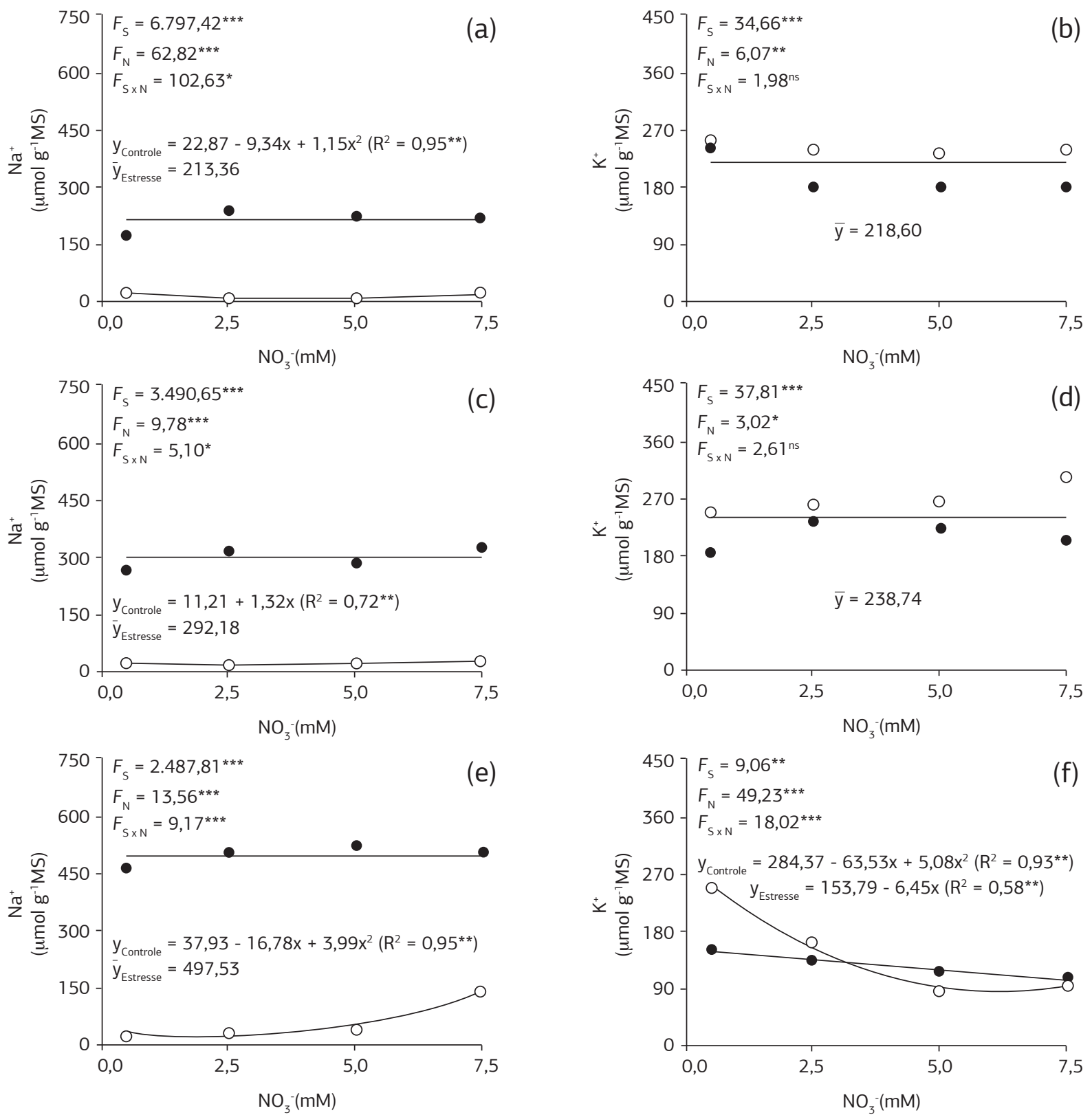

Figura 2. Teores de $\mathrm{Na}^{+}$e $\mathrm{K}^{+}$em folhas (a, b), colmos (c, d) e raízes (e, f) de plantas de milho (Zea mays L.) em condiçóes controle $(\mathrm{O})$ e de estresse salino $(-)$ em funçáo da concentraçáo de $\mathrm{NO}_{3}^{-}$. No canto superior esquerdo, estáo representados os valores de $F$ para salinidade $\left(F_{\mathrm{S}}\right)$, nitrato $\left(F_{\mathrm{N}}\right)$ e interaçáo entre salinidade e nitrato $\left(F_{\mathrm{S} \times \mathrm{N}}\right)$. Níveis de significância: ${ }^{* * *} \mathrm{p} \leq 0,001 ;{ }^{* *} \mathrm{p} \leq 0,01 ;{ }^{*} \mathrm{p} \leq 0,05 ;{ }^{\text {ns }}$ : não significativo.

a resistência das plantas ao estresse salino (DING et al., 2010). Os teores de $\mathrm{NO}_{3}^{-}$nas diversas partes da planta aumentaram com a maior disponibilidade desse íon na solução nutritiva, tanto em condiçóes-controle quanto de estresse salino, havendo interação significativa entre a salinidade e $\mathrm{O}_{3}^{-}$em todos os órgáos analisados (Figura 3b,d,f). A salinidade reduziu a concentraçáo de $\mathrm{NO}_{3}^{-}$nas folhas e nos colmos, mas, nas raízes, houve maior acúmulo desse ânion, em relaçáo ao controle. $\mathrm{O}$ efeito negativo da salinidade na absorção de $\mathrm{NO}_{3}{ }^{-}$já foi relatado em várias espécies com tolerância diferencial ao estresse salino (Rubinigg et al., 2005; TABATABAEI, 2006;
Aragão et al., 2010; Barhoumi et al., 2010; Ding et al., 2010). Esse efeito ocorre devidoà competição direta entre os íons $\mathrm{Cl}^{-} \mathrm{NO}_{3}$ - pelo mesmo transportador e/ou a alteraçóes na integridade da membrana (Mansour e Salama 2004; Rubinigg et al., 2005; Aragão et al., 2010). Contudo, neste estudo, as raízes acumularam mais $\mathrm{NO}_{3}^{-}$em condiçôes salinas do que em condiçôes-controle (Figura 3f), similarmente ao que foi observado por ABD-El BAKI et al. (2000). Uma vez que o carregamento de $\mathrm{NO}_{3}^{-}$no xilema depende do $\mathrm{NO}_{3}{ }^{-}$citosólico, provavelmente grande parte do $\mathrm{NO}_{3}^{-}$absorvido deve ter se acumulado no vacúolo das células radiculares, contribuindo para o ajustamento 

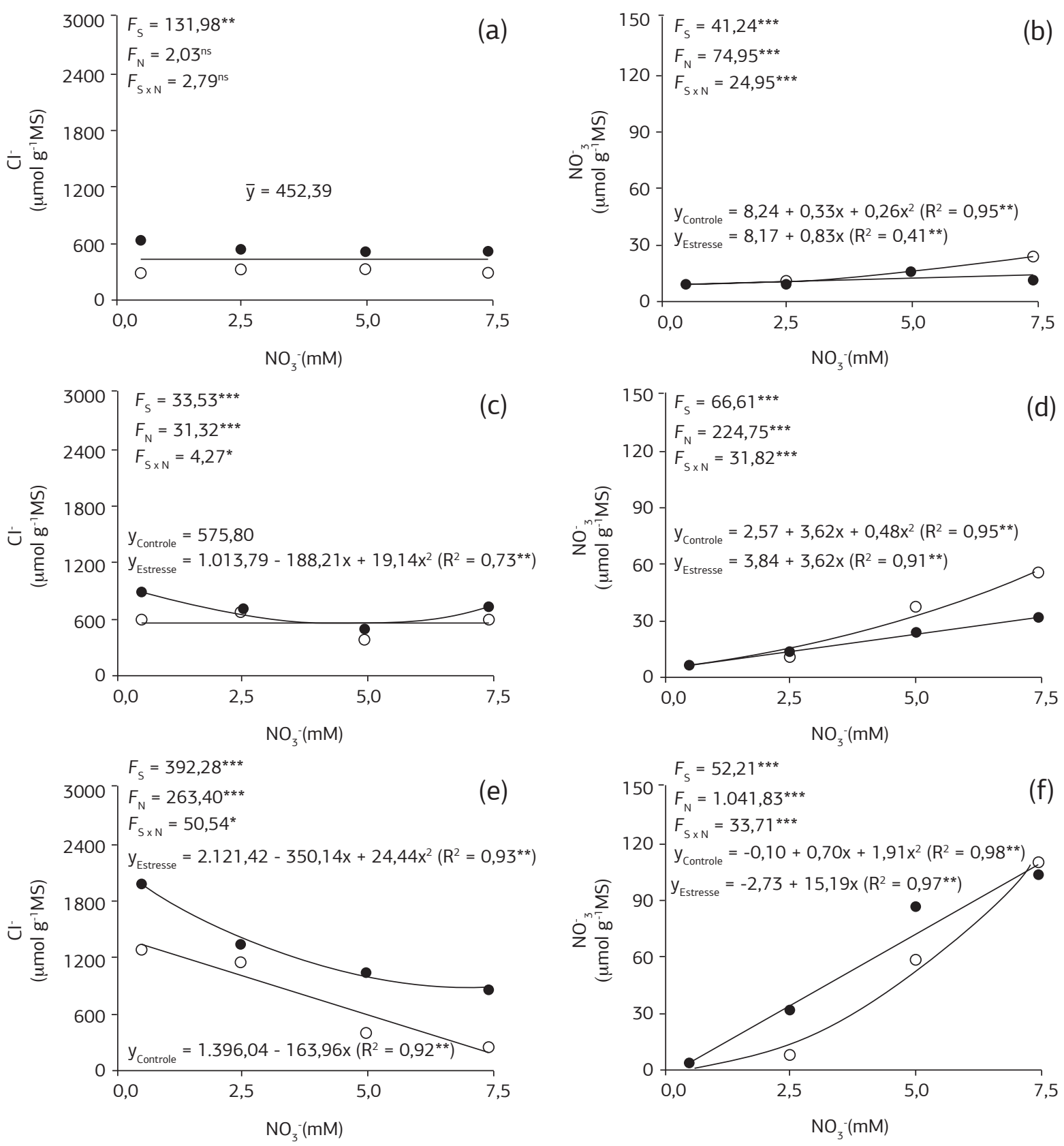

Figura 3. Teores de $\mathrm{Cl}^{-}$e $\mathrm{NO}_{3}^{-}$em folhas (a, b), colmos (c, d) e raízes (e, f) de plantas de milho (Zea mays L.) em condiçôes controle ( $\mathrm{O}$ ) e de estresse salino $(\mathbf{O})$ em função da concentração de $\mathrm{NO}_{3}$. No canto superior esquerdo, estáo representados os valores de $F$ para salinidade $\left(F_{\mathrm{S}}\right)$, nitrato $\left(F_{\mathrm{N}}\right)$ e interação entre salinidade e nitrato $\left(F_{S \times \mathrm{N}}\right)$. Níveis de significância: ${ }^{* * *} \mathrm{p} \leq 0,001 ;{ }^{* *} \mathrm{p} \leq 0,01 ;{ }^{*} \mathrm{p} \leq 0,05 ;{ }^{\text {ns }}$ : não significativo.

osmótico nessas plantas (Miller et al., 2007; Ding et al., 2010). Além disso, o transporte de $\mathrm{NO}_{3}{ }^{-}$das raízes para a parte aérea é prejudicado em condiçōes salinas, como observado por Aragáo et al. (2010) em plantas de feijão-de-corda. Esses autores relataram que a salinidade afetou mais negativamente o fluxo de nitrato no xilema do que os processos de absorção e assimilação desse íon (ARAGão et al., 2010). O maior acúmulo de $\mathrm{NO}_{3}^{-}$nas raízes, em condiçóes salinas, também pode ser explicado por um desequilíbrio entre as taxas de absorção e a assimilação de $\mathrm{NO}_{3}^{-}$(ABD-EL BAKI et al., 2000; YAO et al., 2008).
Nas folhas, apesar dos teores de carboidratos terem sido significativamente afetados pela salinidade e pelo nitrato, não houve interação significativa entre esses dois fatores (Figura 4a). Nos colmos e nas raízes das plantas de milho, órgãos em que houve interação significativa entre a salinidade e o $\mathrm{NO}_{3}^{-}$, os teores de carboidratos foram reduzidos pela salinidade (Figura 4b,c); nas condiçóes-controle, eles pareceram ser ditados, principalmente, por sua demanda na assimilação do $\mathrm{NO}_{3}^{-} \mathrm{em}$ proteínas, aminoácidos etc., uma vez que são necessários esqueletos de carbono para a síntese desses compostos 
(TAiz e Zeiger, 2009), como demonstrado pela redução nos teores de carboidratos nas maiores concentraçóes de $\mathrm{NO}_{3}^{-}$(Figura 4b,c). Azevedo Neto et al. (2004) relacionaram o aumento dos teores de carboidratos solúveis nas folhas de plantas de milho sob estresse salino com o ajustamento osmótico. Entretanto, neste estudo, os teores dos carboidratos solúveis, em condições salinas, não puderam ser correlacionados com o metabolismo do $\mathrm{N}$ nem com o ajustamento osmótico.

Os teores de $\mathrm{N}$-aminossolúveis nas folhas aumentaram linearmente com a concentração crescente de $\mathrm{NO}_{3}^{-}$, não havendo diferença significativa entre os tratamentos controle e salino (Figura 5a). Nos colmos, esse aumento foi linear apenas nas plantas mantidas em condiçóes-controle, contudo, em condiçôes salinas, os teores de $\mathrm{N}$-aminossolúveis ajustaram-se ao modelo quadrático de regressão e foram máximos na concentração estimada de $\mathrm{NO}_{3}^{-}$de $5,8 \mathrm{mM}$ (Figura 5c). Nas raízes, esses teores foram máximos nas concentraçóes estimadas de $\mathrm{NO}_{3}$ - de 6,3 e 4,8 mM, respectivamente, em condiçóes-controle e de estresse salino (Figura 5e).

Os teores de prolina nas folhas comportaram-se de maneira semelhante aos de $\mathrm{N}$-aminossolúveis (Figura $5 \mathrm{~b}$ ). Nos colmos, não houve efeito interativo entre a salinidade e o $\mathrm{NO}_{3}^{-}$, mas o aumento da concentração deste último resultou em um teor de prolina máximo a 4,9 mM (Figura 5d). Nas raízes, em condiçôes-controle, os teores de prolina foram máximos na concentração estimada de 4,9 $\mathrm{mM}$ de $\mathrm{NO}_{3}^{-}$, e, em condiçóes de estresse salino, aumentaram linearmente com a concentraçáo crescente de $\mathrm{NO}_{3}^{-}$no meio de cultivo e, quando a concentraçáo de $\mathrm{NO}_{3}^{-}$estava alta, foram mais elevados do que em condiçóes-controle (Figura 5f).

Tanto os teores de $\mathrm{N}$-aminossolúveis quanto os de prolina foram menores quando a planta foi submetida a baixas concentraçôes de $\mathrm{NO}_{3}^{-}$; este processo indica que a síntese de prolina e outros aminoácidos foi limitada devido à deficiência de $\mathrm{N}$ (Figura 5). Os teores de $\mathrm{N}$-aminossolúveis e prolina, dependendo do órgão e do tratamento salino, ajustaram-se ora ao modelo quadrático de regressão, ora ao modelo linear. No primeiro caso, o aumento do $\mathrm{NO}_{3}^{-}$no meio de cultivo, a partir da concentraçáo correspondente aos valores máximos dos teores de prolina e de $\mathrm{N}$-aminossolúveis, diminuiu o acúmulo desses compostos, indicando pos-

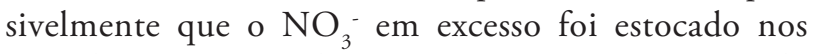
vacúolos. No segundo caso, o $\mathrm{NO}_{3}^{-}$parece ter sido utilizado para a síntese de prolina e $\mathrm{N}$-aminossolúveis à medida que foi absorvido. Por meio de alguns estudos, verifica-se que a prolina e outros aminoácidos desempenham importante papel no balanço osmótico de células sob estresse salino e hídrico, além de estabilizar estruturas subcelulares (membranas e proteínas) sob condições de estresse (Parida e Das, 2005). $\mathrm{O}$ acúmulo desses compostos em plantas sob estresse

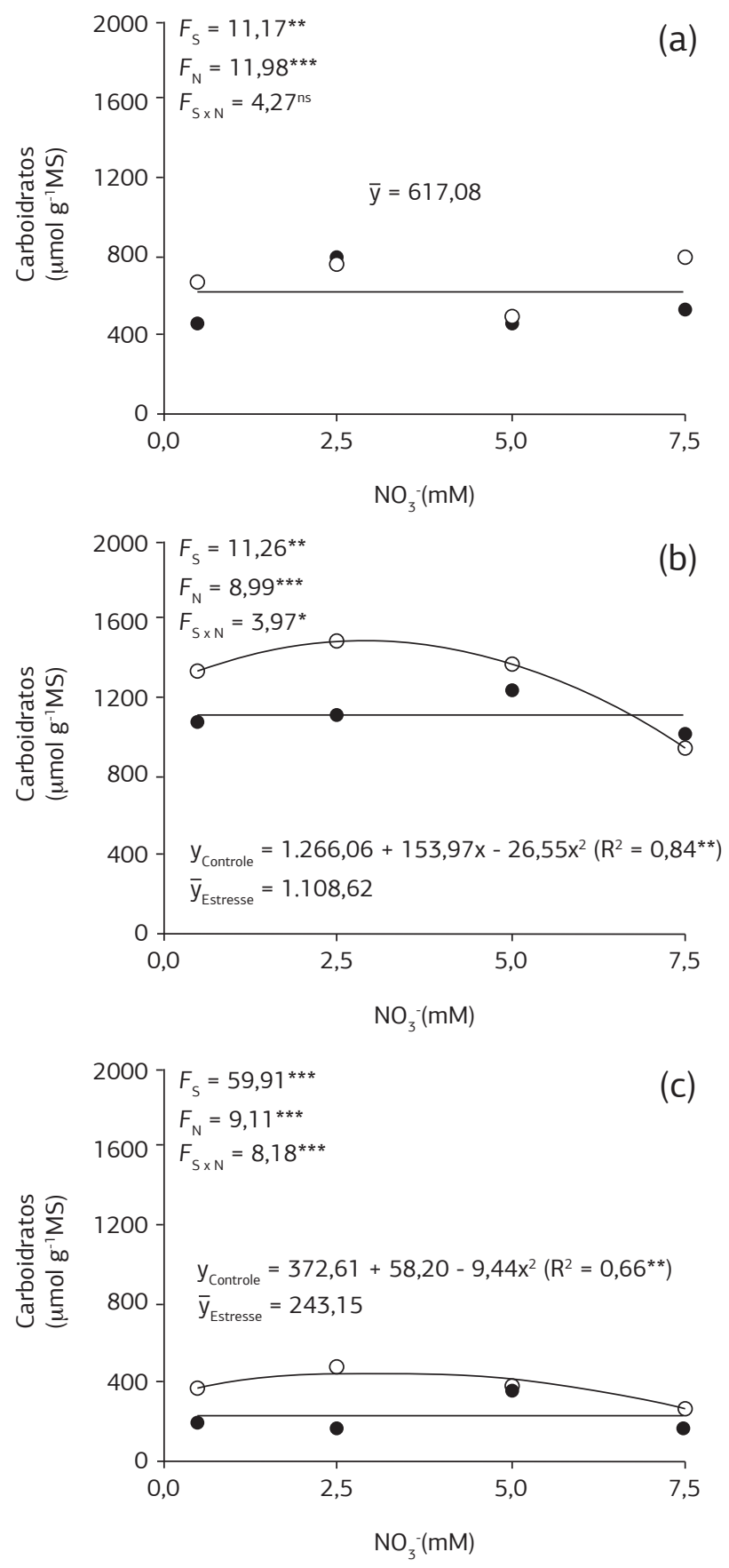

Figura 4. Teores de carboidratos solúveis em folhas (a), colmos (b) e raízes (c) de plantas de milho (Zea mays L.) em condiçóes controle $(\bigcirc)$ e de estresse salino $(\mathbf{)})$ em função da concentração de $\mathrm{NO}_{3}$. No canto superior esquerdo, estáo representados os valores de $F$ para salinidade $\left(F_{\mathrm{S}}\right)$, nitrato $\left(F_{\mathrm{N}}\right)$ e interaçáo entre salinidade e nitrato $\left(F_{S \times N}\right)$. Níveis de significância: ${ }^{* * *} \mathrm{p} \leq 0,001 ;{ }^{* *} \mathrm{p} \leq 0,01$; ${ }^{*} \mathrm{p} \leq 0,05 ;{ }^{\text {ns: }}$ não significativo.

salino vem sendo proposto como marcador fisiológico durante a seleção para tolerância à salinidade (Azevedo Neto et al., 2004; 2009), contudo, neste trabalho, as variaçôes nos teores de $\mathrm{N}$-aminossolúveis e prolina não foram suficientes para predizer o papel desses compostos na resposta das plantas de milho à salinidade. 

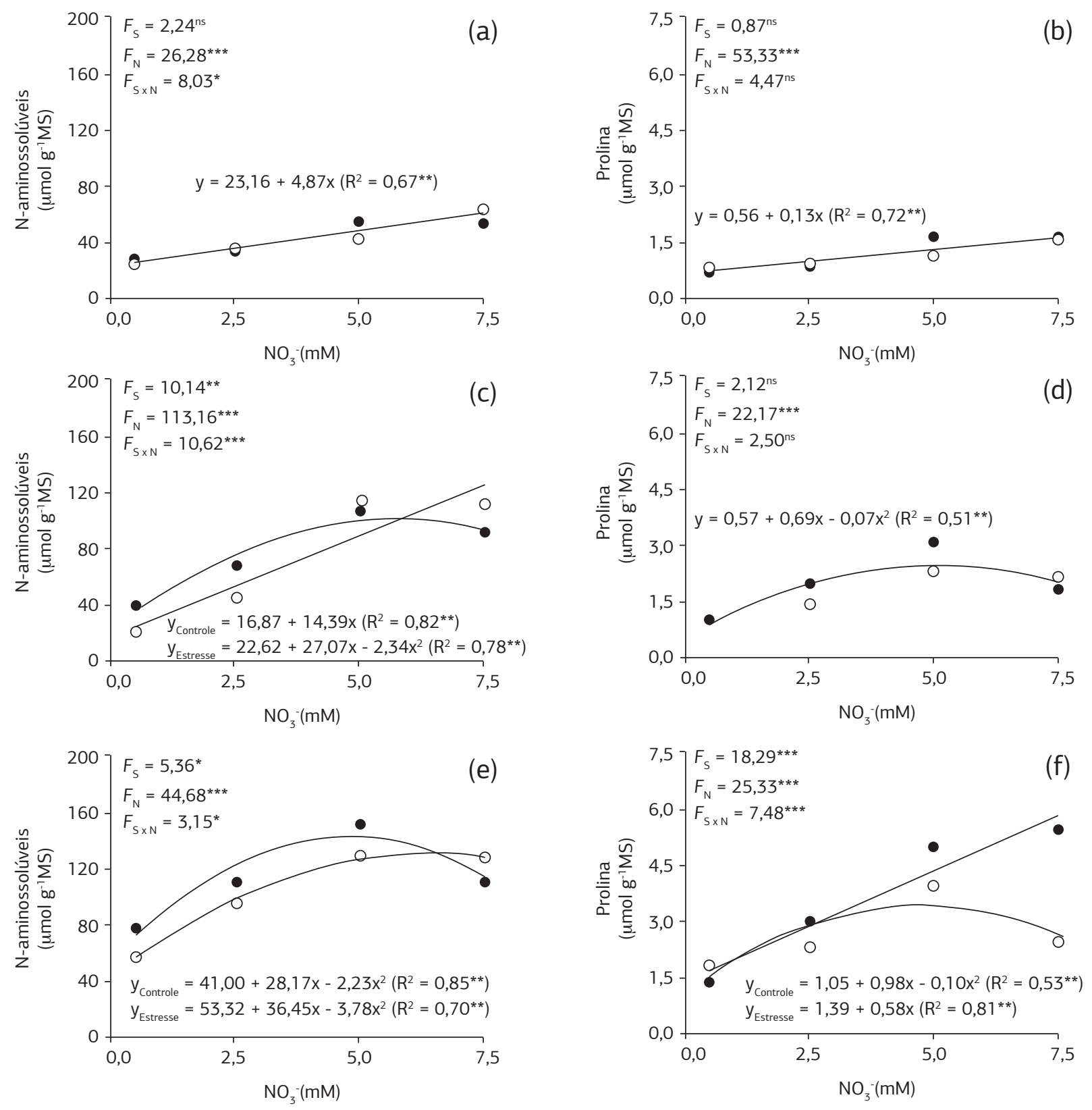

Figura 5. Teores de $\mathrm{N}$-aminossolúveis e prolina em folhas (a, b), colmos (c, d) e raízes (e, f) de plantas de milho (Zea mays L.) em condiçóes controle $(\bigcirc)$ e de estresse salino $(-)$ em função da concentração de $\mathrm{NO}_{3}^{-}$. No canto superior esquerdo, estáo representados os valores de $F$ para salinidade $\left(F_{\mathrm{S}}\right)$, nitrato $\left(F_{\mathrm{N}}\right)$ e interação entre salinidade e nitrato $\left(F_{\mathrm{S} \times \mathrm{N}}\right)$. Níveis de significância: ${ }^{* * *} \mathrm{p} \leq 0,001 ;{ }^{* *} \mathrm{p} \leq 0,01 ;{ }^{*} \mathrm{p} \leq 0,05$; ns: não significativo.

\section{CONCLUSÃO}

O estresse nutricional é mais limitante ao crescimento que o estresse salino quando as plantas de milho são submetidas a baixas concentraçôes de nitrato. Uma nutrição de $\mathrm{NO}_{3}^{-}$adequada alivia os efeitos do estresse salino, pois promove melhor crescimento e reduz o acúmulo de $\mathrm{Cl}^{-}$, além de aumentar os teores de prolina e $\mathrm{N}$-aminossolúveis.

\section{AGRADECIMENTOS}

Ao Conselho Nacional de Desenvolvimento Científico e Tecnológico (CNPq), à Fundação Cearense de Apoio ao Desenvolvimento Científico e Tecnológico (FUNCAP) e ao Instituto Nacional de Ciência e Tecnologia em Salinidade (INCTSal), pela concessão de bolsas e de recursos financeiros indispensáveis à realização deste trabalho de pesquisa. 


\section{REFERÊNCIAS}

ABD-EL BAKI, G.K.; SIEFRITZ, F; MAN, H.M.; WEINER, H.; KALDENHOFF, R.; KAISER, W.M. Nitrate reductase in Zea mays L. under salinity. Plant, Cell and Environment, v.23, p.515$521,2000$.

ALVAREZ-PIZARRO, J.C.; GOMES-FILHO, E.; LACERDA, C.F.; ALENCAR, N.L.M.; PRISCO, J.T. Salt-induced changes on $\mathrm{H}^{+}$-ATPase activity, sterol and phospholipid content and lipid peroxidation of root plasma membrane from dwarf-cashew (Anacardium occidentale L.) seedlings. Plant Growth Regulation, v.59, p.125-135, 2009.

ARAGÃO, R.M.; SILVEIRA, J.A.G.; SILVA, E.N.; LOBO, A.K.M.; DUTRA, A.T.B. Absorção, fluxo no xilema e assimilação do nitrato em feijão-caupi submetido à salinidade. Revista Ciência Agronômica, v.41, p.100-106, 2010.

AZEVEDO NETO, A.D.; PRISCO, J.T.; ENÉAS-FILHO, J.; LACERDA, C.F.; SILVA, J.V.; COSTA, P.H.A.; GOMES-FILHO, E. Effects of salt stress on plant growth, stomatal response and solute accumulation of different maize genotypes. Brazilian Journal of Plant Physiology, v.16, p.31-38. 2004.

AZEVEDO NETO, A.D.; PRISCO, J.T.; GOMES-FILHO, E. Changes in soluble amino- $\mathrm{N}$, soluble proteins and free amino acids in leaves and roots of salt-stressed maize genotypes. Journal of Plant Interactions, v.4, p.137-144, 2009.

BARHOUMI, Z.; ATIA, A.; RABHI, M.; DJEBALL, W.; ABDELLY, C.; SMAOUI, A. Nitrogen and $\mathrm{NaCl}$ salinity effects on the growth and nutrient acquisition of the grasses Aeluropus littoralis, Catapodium rigidum, and Brachypodium distachyum. Journal of Plant Nutrition and Soil Science, v.173, p.149-157, 2010.

BATES, L.S.; WALDREN, R.P.; TEARE, I.D. Rapid determination of free proline for water-stress studies. Plant and Soil, v.39, p.205207, 1973.

CARPICI, E.B.; CELIK, N.; BAYRAM, G. The effects of salt stress on the growth, biochemical parameter and mineral element content of some maize (Zea mays L.) cultivars. African Journal of Biotechnology, v.9, p.6937-6942, 2010.

CATALDO, D.A.; HAROON, M.; SCHRADER, L.E.; YOUNGS, V.L. Rapid colorimetric determination of nitrate in plant tissue by nitration of salicylic. Communications in Soil Science and Plant Analysis, v.6, p.71-80, 1975.

CLARK, R.B. Characterization of phosphatase of intact maize roots. Journal of Agricultural and Food Chemistry, v.23, p.458460, 1975.

DEBOUBA, M.; GOUIA, H.; VALADIER, M.-H, GHORBEL, M.H.; SUZUKI, A. Salinity-induced tissue-specific diurnal changes in nitrogen assimilatory enzymes in tomato seedlings grown under high or low nitrate medium. Plant Physiology and Biochemistry, v.44, p.409-419, 2006.

DING, X.; TIAN, C.; ZHANG, S.; SONG, J.; ZHANG, F.; MI, G.; FENG, G. Effects of $\mathrm{NO}_{3}^{-}-\mathrm{N}$ on the growth and salinity tolerance of Tamarix laxa Willd. Plant and Soil, v.331, p. $57-67,2010$.

DUBOIS, M.; GILLES, K.A.; HAMILTON, J.K.; REBERS, P.A.; SMITH, F. Colorimetric method for determination of sugars and related substances. Analytical Chemistry, v.28, p.350-356, 1956.

EBERT, G.; EBERLE, J.; ALI-DINAR, H.; LÜDDERS, P. Ameliorating effects of $\mathrm{Ca}\left(\mathrm{NO}_{3}\right)_{2}$ on growth, mineral uptake and photosynthesis of $\mathrm{NaCl}$-stressed guava seedlings (Psidium guajava L.). Scientia Horticulturae, v.93, p.125-135, 2002.

FAGERIA, N.K.; GHEYI, H.R.; MOREIRA, A. Nutrient bioavailability in salt affected soils. Journal of Plant Nutrition, v.34, p.945-962, 2011.

FLOWERS, T.J. Improving crop salt tolerance. Journal of Experimental Botany, v.55, p.307-319, 2004.

GAINES, T.P.; PARKER, M.B.; GASCHO, G.J. Automated determination of chlorides in soil and plant tissue by sodium nitrate. Agronomy Journal, v.76, p.371-374, 1984.

MAAS, E.V.; HOFFMAN, G.J. Crop salt tolerance - current assessment. Journal of Irrigation and Drainage Division, v.103, p.115-134, 1977.

MACHADO, F.O.; MAGALHÂES, P.C.; MARRIEL; GAMA, E.E.G.; OLIVEIRA, A.C.; CANTÃO, F.R. Caracterização de genótipos para uso e eficiência de nitrogênio em milho e influência da adubação nitrogenada sobre a incidência e severidade da mancha foliar de Phaeosphaeria maydis. Sete Lagoas: Embrapa Milho e Sorgo, 2004. 8p. (Embrapa Milho e Sorgo. Circular Técnica, 53)

MANSOUR, M.M.F.; SALAMA, K.H.A. Cellular basis of salinity tolerance in plants. Environmental and Experimental Botany, v.52, p.113-122, 2004.

McALLISTER, C.H.; BEATTY, P.H.; GOOD, A.G. Engineering nitrogen use efficient crop plants: the current status. Plant Biotechnology Journal, v.10, p.1011-1025, 2012.

MILLER, A.J.; FAN, X.; ORSEL, M.; SMITH, S.J.; WELLS, D.M. Nitrate transport and signaling. Journal of Experimental Botany, v.58, p.2297-2306, 2007.

MUNNS, R. Comparative physiology of salt and water stress. Plant, Cell and Environment, v.25, p.239-250, 2002.

MUNNS, R.; TESTER, M. Mechanisms of salinity tolerance. Annual Review of Plant Biology, v.59, p.651-681, 2008.

PARIDA, A.K.; DAS, A.B. Salt tolerance and salinity effects on plants: a review. Ecotoxicology and Environment Safety, v.60, p.324-349, 2005.

RODRIGUES, C.R.F.; SILVA, E.N.; FERREIRA-SILVA, S.L.; VOIGT, E.L.; VIÉGAS, R.A.; SILVEIRA, J.A.G. High $\mathrm{K}^{+}$supply avoids $\mathrm{Na}^{+}$toxicity and improves photosynthesis by allowing favorable $\mathrm{K}^{+}: \mathrm{Na}^{+}$ratios through the inhibition of $\mathrm{Na}+$ uptake and transport to the shoots of Jatropha curcas plants. Journal of Plant Nutrition and Soil Science, v.176, p.157-164, 2013. 
RUBINIGG, M.; POSTHUMUS, F.S.; ELZENGA, J.T.M.; STULEN, I. Effect of $\mathrm{NaCl}$ salinity on nitrate uptake in Plantago maritima L. Phyton, v.45, p.295-302, 2005.

TABATABAEI, S.J. Effects of salinity and $\mathrm{N}$ on the growth, photosynthesis and $\mathrm{N}$ status of olive (Olea europaea L.) trees. Scientia Horticulturae, v.108, p.432-438, 2006.

WILLIAMS, L.E.; MILLER, A.J. Transporters responsible for the uptake and partitioning of nitrogenous solutes. Annual
Review of Plant Physiology and Plant Molecular Biology, v.52, p.659-688, 2001.

YAO, J.; SHI, W.M.; XU, W.F. Effects of salt stress on expression of nitrate transporter and assimilation-related genes in tomato roots. Russian Journal of Plant Physiology, v.55, p.232-240, 2008.

YEMM, E.W.; COCKING, E.C. The determination of aminoacids with ninhydrin. Analyst, v.80, p.209-213, 1955. 